\title{
Eosinophilic Pneumonias
}

\author{
Praveen Akuthota ${ }^{a, b}$ and Peter F. Weller ${ }^{b, c}$ \\ Division of Pulmonary, Critical Care, and Sleep Medicine, Department of Medicine, Beth Israel Deaconess Medical Center, Harvard Medical School, Boston, Massachusetts, \\ USA ${ }^{\mathrm{a}}$; Division of Allergy and Inflammation, Department of Medicine, Beth Israel Deaconess Medical Center, Harvard Medical School, Boston, Massachusetts, USA \\ Division of Infectious Diseases, Department of Medicine, Beth Israel Deaconess Medical Center, Harvard Medical School, Boston, Massachusetts, USA ${ }^{c}$
}

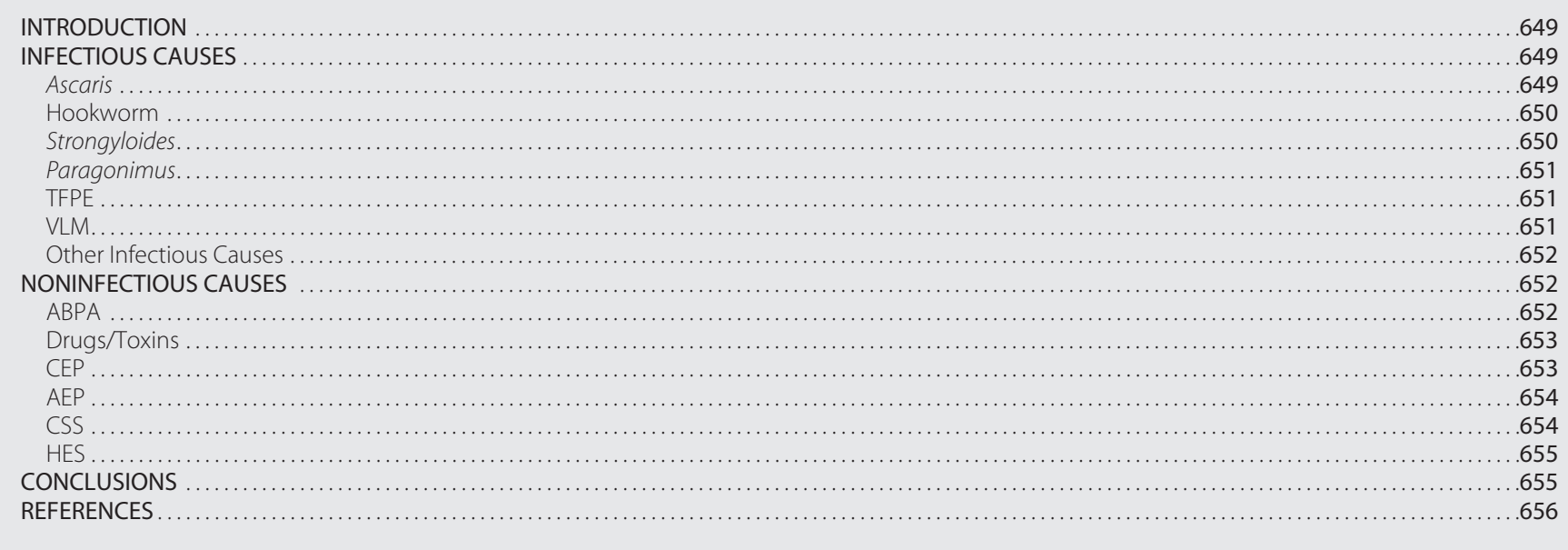

\section{INTRODUCTION}

T he terms "eosinophilic pneumonia" and "pulmonary eosinophilia" loosely encompass a broad range of infectious and noninfectious pulmonary conditions that involve infiltration of eosinophils into the lungs, often with accompanying peripheral blood eosinophilia. Conditions in which airway and peripheral eosinophilias are present in the absence of parenchymal infiltration and radiographic changes, such as allergic asthma, are not included in this broad categorization. This review starts with discussions of several infectious causes of eosinophilic pneumonia, which are almost exclusively parasitic in nature. Inclusion of these parasitic etiologies in the differential diagnosis of pulmonary eosinophilia depends highly on epidemiologic considerations that make exposure to the offending organisms more likely. Pulmonary infections due specifically to Ascaris, hookworms, Strongyloides, Paragonimus, filarial nematodes, and Toxocara are considered in detail. The discussion then moves to noninfectious causes of eosinophilic pulmonary infiltration, including allergic sensitization to Aspergillus, acute and chronic eosinophilic pneumonias (AEP and CEP, respectively), Churg-Strauss syndrome (CSS), hypereosinophilic syndromes (HES), and pulmonary eosinophilia due to exposure to specific medications or toxins.

Eosinophil immunobiology is complex and has been reviewed elsewhere $(2,155)$. However, certain considerations warrant particular mention in a discussion of pulmonary eosinophilia. Eosinophils are integral components of Th2 inflammation (155), a prominent feature of most of the conditions discussed in this review. The presence of the cytokine interleukin-5 (IL-5) in particular is central to eosinophilia, promoting the differentiation, survival, and migration of eosinophils (31, 162, 200, 216). Also important as a common pathophysiologic mechanism of pulmo- nary tissue damage in the eosinophilic pneumonias is the release of cytotoxic, granule-stored cationic proteins by eosinophils (155). Eosinophils have intricate immunoregulatory functions that are likely important in orchestrating the perpetuation of Th2 inflammation in the eosinophilic pneumonias.

\section{INFECTIOUS CAUSES}

\section{Ascaris}

Pulmonary eosinophilia due to the passage of helminth larvae through the lungs is referred to as Löffler's syndrome, though the term is often used more generally to refer to simple pulmonary eosinophilia from any fungal, parasitic, or drug-induced cause. In the original case series by Löffler, most of the cases described were due to Ascaris infections (98). Human pulmonary eosinophilia caused by Ascaris has been described for Ascaris lumbricoides (98) and Ascaris suum (144).

Eosinophilic pulmonary infiltrates and respiratory symptoms due to Ascaris are generally part of a self-limited process due to the transient nature of larval passage through the lungs in the Ascaris life cycle (38). Though many patients remain asymptomatic, 8 to $15 \%$ of infected individuals display morbidity, with respiratory symptoms occurring 9 to 12 days after the ingestion of eggs and lasting 5 to 10 days $(39,211)$. The severity of the clinical syndrome has been noted to correlate with the extent of worm burden (39). Ingestion of A. lumbricoides eggs may occur due to the use of

Address correspondence to Peter F.Weller, pweller@bidmc.harvard.edu. Copyright $\odot$ 2012, American Society for Microbiology. All Rights Reserved. doi:10.1128/CMR.00025-12 
human feces contaminated with Ascaris eggs as fertilizer, as described in Löffler's case series $(38,98,211)$. Infection with $A$. suum may take place when there is close domestic proximity between pigs and humans (38), though a prominent case series of Löffler's syndrome due to A. suum occurred in patients whose food was maliciously contaminated (144). Symptoms may include cough, dyspnea, wheeze, and hemoptysis and may progress to frank respiratory distress $(98,144)$. Peripheral eosinophilia (i.e., absolute eosinophil count of $>500 /$ microliter) is often present at the onset of symptoms, but the peak level of eosinophilia will have a delay of several days from presentation $(144,211)$. If necessary, definitive diagnosis can be made by recovery of Ascaris larvae from either respiratory secretions or gastric lavage fluid $(144,211)$. Eggs will not be detectable in the stool at this early stage in the nematode life cycle. The radiographic pattern found at the time of respiratory symptoms is characterized by patchy areas of consolidation that may coalesce in more severe cases (45). Because pulmonary eosinophilia due to Ascaris is self-limited, specific therapy at the time of symptoms is generally not necessary (38). Corticosteroids may be administered in particularly severe cases and have been observed to result in favorable symptomatic responses $(48,144)$. Therapy aimed at eradication of adult worms with albendazole or mebendazole should be delayed until after pulmonary symptoms have resolved and organisms are expected to have entered the adult phase (38).

A. suum infection has been reported to result in a visceral larval migrans (VLM) pattern of pulmonary eosinophilia (107, 133, 160). However, whether these cases are truly representative of Ascaris-associated VLM, with liver and lung involvement, rather than either VLM due to Toxocara or misclassified Löffler's syndrome, remains an unresolved issue (142).

\section{Hookworm}

Though such cases are uncommon, Löffler's syndrome may occur after infection with Ancylostoma duodenale or Necator americanus as larvae migrate through the lungs $(10,45,61,96,163)$. Initial infection occurs exclusively by the percutaneous route in the case of $N$. americanus and by either the oral or percutaneous route in the case of $A$. duodenale (61). Respiratory symptoms are usually mild and occur several days after the onset of infection (207). As with Löffler's syndrome due to Ascaris, pulmonary symptoms, which include wheeze, cough, and hemoptysis, are accompanied by transient infiltrates on chest imaging and peripheral blood eosinophilia (45). In experimental low-dose N. americanus infection of human volunteers, bronchoscopy performed at the time that larvae were expected to be transiting through the lung demonstrated erythema of the airways (111). Also in common with Ascaris is the necessity of isolation of hookworm larvae in respiratory or upper gastrointestinal (GI) secretions in order to definitively make the diagnosis, as isolation of hookworm eggs from the stool will not occur for several months after the transient pulmonary component of the syndrome (207). Treatment with a benzimidazole agent is necessary for eradication of adult worms but will not affect the potential pulmonary component of hookworm infection. Corticosteroids may be used if Löffler's syndrome results in severe respiratory symptoms (207). Löffler's syndrome associated with cutaneous larval migrans secondary to animal hookworms, such as Ancylostoma braziliense, has also been reported but is rare $(35,141,183,214)$.

Notably, experimental hookworm infection in rodents has proven to be a valuable tool in the study of Th2 inflammation and eosinophil recruitment to the lungs, taking advantage of the pulmonary transmigration component of the hookworm life cycle (2, 32). Specific to eosinophilic pneumonias is the observation of increased eosinophil chemoattractant production in the lungs coinciding with the presence of larvae in mice infected with N. americanus (32).

\section{Strongyloides}

While initial Strongyloides stercoralis infection by filariform larvae through a transcutaneous route may result in Löffler's syndrome, this is not a common pulmonary manifestation of strongyloidiasis $(175,207,211)$. However, Strongyloides may cause pulmonary symptoms and infiltrates as a manifestation of chronic infection or as a result of hyperinfection in immunocompromised hosts (207). The unique life cycle of S. stercoralis allows a chronic infection of extended duration to occur due to the ability of new filariform larvae to continuously autoinfect the human host through the perianal skin or bowel mucosa (175). Patients with chronic infection may have repeated episodes of fever and pneumonitis that may be mistaken for recurrent bacterial pneumonias (207). Eosinophilia, though often absent during the acute episodes, may occur during the intervening period between episodes (207). Pulmonary involvement of strongyloidiasis has been reported as an asthma mimic (128).

Serious, potentially fatal pulmonary infections may occur in the context of the hyperinfection syndrome, resulting from heavy parasite burdens, most often in immunocompromised hosts with deficiencies in cell-mediated immunity $(49,79,97,116,148)$. Symptoms may include dyspnea, cough, pleuritic chest pain, and hemoptysis, accompanied by infiltrates of varying character on chest imaging and often accompanied by a mild blood eosinophilia, unless this is suppressed by concomitant use of corticosteroids or bacterial coinfection $(79,207,211,212)$. Respiratory failure may occur in severe cases (79). Lung abscesses and pleural effusions have been reported as manifestations of pulmonary strongyloidiasis $(44,212)$. Use of corticosteroids, even for short durations, for underlying chronic lung disease or other indications is a risk factor for the development of hyperinfection syndrome with pulmonary involvement $(25,44,49,60,194)$. Though rare, pulmonary strongyloidiasis is a potential complication of HIV/AIDS $(43,51,97,101)$. Several other factors, such as hematologic malignancy, immunosuppressive drug therapy, solid organ transplantation, hematopoietic cell transplantation, human T-cell leukemia virus type 1 (HTLV-1) infection, hypogammaglobulinemia, and malnutrition, have all also been associated with Strongyloides hyperinfection syndrome $(79,164,197)$.

The diagnosis of strongyloidiasis, when suspected in patients with a compatible pulmonary syndrome, can be made by detection of larvae from stool (207). However, because stool studies are often negative due to the small number of larvae usually passed in the stool, aspiration of duodenojejunal fluid and enzyme-linked immunosorbent assay (ELISA) serologic testing may be used as adjunct diagnostic tools $(79,175)$. Rhabditiform larvae may also be detected in bronchoalveolar lavage (BAL) fluid samples or in sputum examinations, establishing the diagnosis $(58,210)$. Ivermectin therapy is the treatment of choice, and therapy may need to be extended beyond the usual 2 days to at least 7 days in cases of hyperinfection syndrome (175). 


\section{Paragonimus}

Eosinophilic pulmonary infections are caused by several species of Paragonimus, the lung fluke (207). Paragonimus infections are generally acquired by the ingestion of raw or undercooked seafood, in particular crabs and crayfish, which serve as secondary hosts in the life cycle of the organism (100). Paragonimus westermani, which is endemic to East and Southeast Asia, is the best characterized of the eight species of lung fluke that are thought to lead to human disease $(100,207)$. It should be noted that Paragonimus infections are not limited to East and Southeast Asia but occur throughout the world, in particular in Central and South America (Paragonimus mexicanus) and West Africa (Paragonimus africanus) (100). While P. westermani has been reported for rare infections contracted in the United States (14), most reports of paragonimiasis in the United States have been due to Paragonimus kellicotti $(91,106,140)$.

Once metacercaria-stage parasites are ingested, they form exocysts in the duodenum that migrate into the peritoneum and through the diaphragm into the lungs (13). As larvae migrate through the upper GI tract and peritoneum, they may initially cause symptoms of abdominal pain and diarrhea after an incubation period of 2 to 15 days $(100,207)$. As organisms penetrate the diaphragm, pleuritic chest pain may develop, with the potential for pneumothorax or pleural effusion $(13,70)$. Pleural effusions caused by Paragonimus are commonly eosinophilic in nature (185). Though the lungs are usually the destination of migrating larvae, paragonimiasis may involve the brain or skin (100). As larvae continue to migrate within the lung parenchyma, symptoms of cough, low-grade fever, and blood-streaked sputum may occur, accompanied by infiltrates on chest imaging and prominent peripheral blood eosinophilia (10 to $30 \%$ of circulating leukocytes) $(13,207)$. The infection then progresses to a chronic phase within the lung, which may last up to several years, characterized by chronic cough and recurrent hemoptysis with resolution of the previously seen blood eosinophilia (70, 207). During this phase, larvae mature into mature flukes surrounded by a fibrous capsule that forms after the initial period of neutrophilic and eosinophilic inflammation (100). Eosinophil degranulation caused by secreted parasitic proteins may contribute to local inflammation and subsequent fibrous cyst formation (26). The mature flukes produce eggs that are coughed and expectorated or swallowed after rupture of cysts into communicating airways (45).

Chest X-rays may show no abnormality for approximately $20 \%$ of infected patients $(45,130)$. When abnormalities are noted on chest X-ray or computed tomography (CT) scan, they are varied in nature, often consisting of parenchymal opacities that may be either hazy and ill-defined in nature or more nodular (72, 130, 217). Thin-walled cysts may be noted, as well as linear opacities corresponding to burrowing organisms $(63,64,83,176)$.

The diagnosis of Paragonimus infection is made by identification of eggs in sputum, stool, or gastric aspirates (100). Praziquantel is generally the preferred drug for treatment (71).

\section{TFPE}

Infections with the filarial nematodes Wuchereria bancrofti, Brugia malayi, and Brugia timori lead to lymphatic filariasis, a manifestation of which is a distinct eosinophilic pulmonary process known as tropical filarial pulmonary eosinophilia (TFPE) (138). True to its name, TFPE occurs in individuals from tropical regions, in-
A

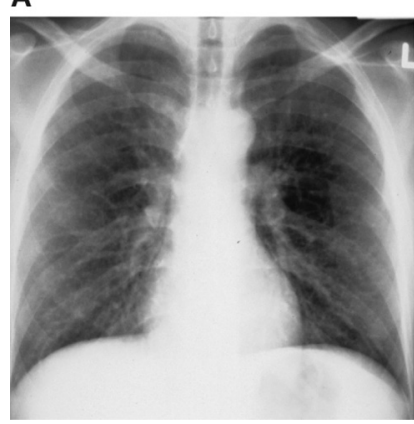

B

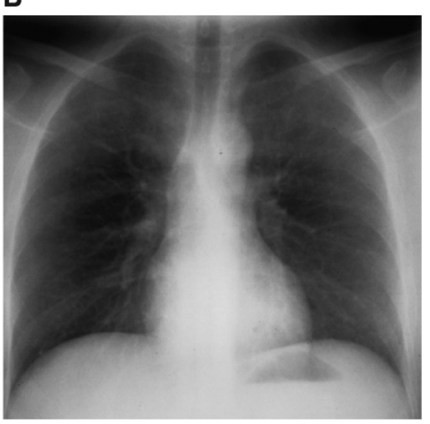

FIG 1 Chest X-rays of tropical filarial pulmonary eosinophilia before (A) and after (B) treatment with diethylcarbamazine.

cluding but not limited to the Indian subcontinent, Southeast Asia, parts of Africa, and parts of China, or in individuals who have traveled to these regions (126). Humans are infected by third-stage larvae after a bite from a mosquito taking a blood meal. Larvae then mature to male and female adult worms, which mate to produce microfilariae. These are then ingested by mosquitos taking blood meals, followed by subsequent maturation to thirdstage larvae, completing the life cycle of the organism (126). The pathogenesis of TFPE has not been clarified fully, but a strong eosinophilic immunologic response to microfilariae trapped in the lungs likely plays a pivotal role $(129,145,202)$. Interestingly, only a small percentage of patients affected with lymphatic filariasis develop pulmonary manifestations, and there is a strong male predominance in developing TFPE $(126,207)$. The clinical presentation of TFPE is characterized by the gradual onset of paroxysmal asthma-like symptoms and nonproductive cough. Constitutional symptoms of weight loss and fatigue are commonly present as well (126). Chest imaging in TFPE demonstrates reticulonodular opacities with nodules of 1 to $3 \mathrm{~mm}$ (Fig. 1) $(45,211)$. Pulmonary function testing can show both restrictive and obstructive patterns of abnormality (193).

In addition to the clinical presentation and radiographic findings, diagnosis is aided by the presence of a peripheral eosinophilia, which may be high grade and is generally $>3,000 /$ microliter. Eosinophils are also present in BAL fluid specimens (145). Serum IgE is elevated in TFPE (127). While not specific for the type of filiarial infection, serologic antibody testing can confirm the diagnosis (90). ELISA testing for antigen from $W$. bancrofti is also available (117).

Though not needed for diagnosis, pathology specimens of the lung during TFPE are characterized initially by eosinophilic infiltration that progresses to eosinophilic abscesses and eosinophilic granulomas. As the disease progresses unchecked, fibrosis may develop. Microfilarial fragments are occasionally identifiable on lung specimens (193).

Patients with TFPE are treated with diethylcarbamazine, with the option of using doxycycline as an adjunct therapy against adult worms. Relapses are also treated with the same regimen $(137,152$, 187).

\section{VLM}

VLM is a syndrome due to infection by the dog ascarid, Toxocara canis, or the cat ascarid, Toxocara cati, that commonly includes pulmonary eosinophilia (9). Humans are accidental hosts for Toxo- 
TABLE 1 Infectious causes of eosinophilic pneumonia

\begin{tabular}{ll}
\hline Manifestation of disease & Infectious cause \\
\hline Löffler's syndrome & $\begin{array}{l}\text { Ascaris } \\
\text { Hookworm } \\
\text { Schistosomiasis }\end{array}$ \\
& Strongyloidiasis \\
Heavy parasite burden & $\begin{array}{l}\text { Paragonimiasis } \\
\text { Visceral larval migrans }\end{array}$ \\
& Filariasis \\
Immunologic response to organisms in lungs & Dirofilariasis \\
& Echinococcus \\
Cystic disease & Cysticercosis \\
& Coccidioidomycosis \\
Other nonparasitic disease & Basidiobolomycosis \\
& Paracoccidioidomycosis
\end{tabular}

cara; larvae cannot mature into adults in humans and migrate through tissues, causing disease $(36,207)$. VLM is predominately a disease of children between the ages of 1 and 5 years, as the infection is usually acquired through the ingestion of embryonated eggs in soil contaminated with dog feces in areas such as public playgrounds (62). Infections are not generally transmitted directly from dogs or cats, as eggs shed from these animals require approximately 3 weeks in the soil before they become infectious (207).

The clinical syndrome observed from Toxocara infection commonly affects the liver and the lungs, though other tissues, such as the central nervous system and the eyes (ocular larval migrans), may be affected as well $(16,36,113)$. The pulmonary manifestations of VLM are a result of damage from the penetration of larvae into the lungs and from the immunological response to the larvae (78). While some individuals manifest only a peripheral blood eosinophilia, pulmonary symptoms include dyspnea, wheeze, and cough $(9,16,36)$. Symptoms may rarely be severe in nature (8). Chest imaging, when abnormal, demonstrates ill-defined airspace opacities that on CT scan are subpleural in location, with a ground-glass or nodular appearance $(45,160)$. Anti-A or anti-B isohemagglutinin titers are elevated in $50 \%$ of patients with VLM (207). Liver involvement may lead to liver function test abnormalities. ELISA testing available from the U.S. Centers for Disease Control and Prevention can assist in establishing the diagnosis. Because VLM is a self-limited syndrome, specific treatment is usually not required. However, in moderate to severe cases, albendazole may be administered, along with prednisone as an adjunctive therapy.

\section{Other Infectious Causes}

Apart from the parasitic infectious causes of eosinophilic pneumonic processes discussed above, other parasitic and nonparasitic infections may lead to pulmonary eosinophilia. A list of potential infectious causes of pulmonary eosinophilia is included in Table 1.

Echinococcal cysts may lead to a pulmonary eosinophilia, particularly in instances of rupture (12). Similarly, while involvement of the lungs is rare in cysticercosis, pulmonary eosinophilia may develop (103). While the major pulmonary complication of schistosomiasis is pulmonary hypertension from chronic infection, a
Löffler's syndrome-like process may occur with initial infection, particularly in previously unexposed individuals and those with high-intensity infections $(29,30)$. Release of eggs into the pulmonary circulation with the initiation of anthelmintic therapy for schistosomiasis has also been observed to result in a transient pulmonary eosinophilia (139). Nonparasitic causes, including Coccidioides, also have the ability to lead to an eosinophilic pneumonia in rare circumstances (99).

\section{NONINFECTIOUS CAUSES}

\section{ABPA}

Allergic sensitization to Aspergillus species may lead to allergic bronchopulmonary aspergillosis (ABPA), a well-characterized eosinophilic pulmonary condition, with the development of asthmatic symptoms, pulmonary infiltrates, central bronchiectasis, and elevated IgE levels $(1,54,191,220)$. Though ABPA is recognized in general to be due to allergic mechanisms in response to the inhalation of Aspergillus rather than due to frank infection, the pathophysiology of the condition is not completely understood. However, Th2 inflammation is a key component of the inflammatory response to Aspergillus spores, with Aspergillus antigen-responsive circulating Th2 cells being identifiable in ABPA patients $(22,88)$. T cell clones specific to the Aspergillus fumigatus Asp f 1 antigen established from patients with ABPA are predominately of the Th2 phenotype (22). The increase in Th2 inflammation accounts for the observed eosinophilia and elevated IgE levels. The costimulatory molecule OX40 ligand has been found to be important in Th2 inflammatory responses in patients with ABPA associated with cystic fibrosis, with increased Th2 activity inversely correlating with circulating vitamin D levels (88). Proteolytic enzymes and mycotoxins from Aspergillus in colonized airways, along with eosinophilic inflammation and neutrophilic inflammation, may cause the characteristic central bronchiectasis seen in many cases of ABPA (50).

The clinical features of ABPA are dominated by asthma symptoms, often with a significant component of cough and expectoration of brownish mucous plugs (1). Peripheral eosinophilia is common, a characteristic that makes it a prominent component of the differential diagnosis for pulmonary eosinophilia in the correct clinical context $(18,21,154)$. Chest X-rays and CT scans of patients with ABPA may classically show patchy infiltrates, bronchiectasis, and evidence of mucous impaction $(1,17,122)$. Central bronchiectasis is associated with ABPA, though its presence on CT scan is not highly sensitive for a diagnosis of ABPA (149). Pulmonary function testing usually shows an obstructive pattern for patients with ABPA $(102,124)$. Though pathology is not necessary for diagnosis, findings are variable, with eosinophilic inflammation, mucoid impaction, and bronchocentric granulomatosis (20, $151,178)$. Noninvasive, septated hyphae may be observed in the distal airways as well.

The diagnosis of ABPA is based not on a single test result but on a constellation of clinical, radiographic, immunologic, and serologic findings based on the known pathophysiology and presentation of the disease $(1,54)$. A diagnosis of ABPA may be made if four of the following major features are present: a history of asthma, positive Aspergillus skin test reactivity, precipitating antibodies to A. fumigatus, elevated total IgE level ( $>417 \mathrm{IU} / \mathrm{ml})$, elevated circulating levels of specific IgE and IgG, peripheral eosinophilia, central bronchiectasis on chest imaging, and pulmonary 
infiltrates (54). An evaluation for ABPA is often undertaken for patients with difficult-to-treat asthma to find an underlying cause for resistance to therapy. ABPA may also occur as a complicating pulmonary condition in a substantial subset of patients with cystic fibrosis and is suspected in those patients whose exacerbations of respiratory symptoms respond poorly to antibiotic therapy (181).

Treatment for acute or recurrent flares of ABPA consists of systemic glucocorticoids as a first-line therapy, with tapering over a 3- to 6-month period (198). Antifungal therapy with agents effective against Aspergillus species, such as itraconazole or voriconazole, may be used as adjunct therapy targeted at reducing the antigenic stimulus driving ABPA activity $(42,182,199)$. The use of antifungal agents has proven effective in improving symptoms and lowering the dose of glucocorticoids in ABPA patients. Omalizumab, a monoclonal antibody against IgE, has also been described in case reports and series as an effective agent in treating ABPA, particularly in those patients with ABPA associated with cystic fibrosis $(94,190,196)$.

Several other fungi have been reported to cause a syndrome similar to ABPA (1). However, these are rare compared to the more common ABPA, which is present in a significant subset of patients with asthma $(55,165)$.

\section{Drugs/Toxins}

A host of medications and toxins, both inhaled and ingested, have been associated with the development of pulmonary eosinophilia (179). The most commonly implicated classes of medications are the nonsteroidal anti-inflammatory medications and antibiotics. While several classes of antibiotics are associated with the development of pulmonary eosinophilia, nitrofurantoin in particular has frequently been described as a culprit. Though these medications are the most commonly associated triggers, the list of medications causing pulmonary eosinophilia is lengthy, and all medications should be reviewed carefully whenever eosinophilia with pulmonary infiltrates occurs. Furthermore, environmental exposures, such as particulate metal exposure and scorpion stings, as well as inhalational drugs of abuse, such as crack cocaine, may lead to eosinophilic pulmonary infiltrates (119, $166,167)$. The presentation of affected patients may vary, from no symptoms to mild respiratory symptoms and cough to a presentation resembling acute eosinophilic pneumonia in severe cases. Treatment consists of removal of the offending medication or toxin, along with glucocorticoid therapy if warranted by the degree of symptoms (179).

\section{CEP}

Chronic eosinophilic pneumonia (CEP) is an idiopathic condition not due to a known infectious or toxic etiology in which eosinophils infiltrate the pulmonary parenchyma and cause symptoms of dyspnea, cough, and hypoxemia of varying severity. Carrington and colleagues first reported CEP in 1969 for a series of 9 female patients presenting with dyspnea, fevers, and weight loss, along with peripheral opacities on chest X-rays and eosinophilic airspace infiltration on lung biopsy specimens (19). These patients had a robust, favorable clinical response to corticosteroid therapy. This first description of CEP remains quite consistent with the current understanding of this syndrome.

The pathophysiology of CEP remains incompletely delineated, though elevations of several cytokine, chemokine, and immuno- modulatory products in studies of BAL fluid obtained from patients with CEP suggest that recruitment of eosinophils into the lung airspaces is a multifactorial process. BAL fluid in CEP contains the cytokines IL-4, IL-5, IL-6, IL-10, IL-13, and IL-18, which is largely consistent with local Th2 inflammation, though the Th1 cytokines IL-2 and IL-12 are present as well $(76,85,114)$. Several chemokines are also present in BAL fluid samples, including CCL17 and CCL22, the chemokine ligands of the receptor CCR4, suggesting that $\mathrm{T}$ cell recruitment may be an important factor in the pathophysiology of CEP $(74,114)$. In addition, CXCL9, CXCL10, CCL5 (RANTES), CCL11 (eotaxin-1), CCL2, and CCL4 have also been observed to be elevated in $\operatorname{CEP}(73,75,89,186)$. Other immune mediators, such as tryptase, prostaglandins, and soluble ADAM8, have been detected to be elevated in the BAL fluid of CEP patients as well $(7,109,132)$. BAL fluid eosinophils in CEP are activated, with expression of HLA-DR, and have longer survival than their counterparts in the peripheral blood, with decreased apoptosis $(11,159)$. There is evidence that eosinophils in CEP have locally augmented secretion of their cytotoxic, cationic granule-stored contents, with detection of increased major basic protein (MBP) and eosinophilic cationic protein (ECP) in lungderived specimens $(15,53,169)$. Eosinophil derived neurotoxin $(\mathrm{EDN})$ has been detected in high levels in the urine of patients with CEP $(37,136)$. Electron microscopy studies have demonstrated lysed eosinophils, degranulation, and the uptake of granule-proteins by alveolar macrophages, as well as the presence of cell-free granules $(52,66)$. T cells also have a likely role in CEP, with increases in activated $\mathrm{CD} 4^{+} \mathrm{T}$ helper cells present in the alveoli, as well as observations of oligoclonal $\mathrm{T}$ cell populations in the BAL fluid $(118,170)$.

CEP is characterized by respiratory and systemic symptoms in the presence of both lung and blood eosinophilia (203). There is a 2:1 female-to-male predominance of CEP, and the disease often occurs in patients with asthma $(104,105)$. The onset of symptoms is indolent and most commonly features cough, dyspnea, malaise, fever, and weight loss (105). While a stringent set of diagnostic criteria have not been established for CEP, peripheral blood eosinophilia is usually present, though not always. The presence of eosinophils in BAL fluid is necessary to establish the diagnosis, with eosinophilia exceeding $40 \%$ of the total cell count observed in more than $80 \%$ of cases (105). Elevations in IgE levels, erythrocyte sedimentation rate, and C-reactive protein may be present as well (105). The original case series of CEP, along with a follow-up radiographic case series, described the chest X-rays of CEP patients as displaying peripheral opacities that are the "photographic negative" of pulmonary edema, which has endured as an identifying characteristic of the disease $(19,121)$, though the lack of this pattern does not exclude CEP $(68,105)$. CT imaging of the chest most often shows patchy airspace consolidations with a peripheral distribution, though patterns may vary $(46,105,112,115)$. A representative chest X-ray and CT scan image from a patient with CEP are displayed in Fig. 2. Pleural effusions have been reported as a rare manifestation of CEP, as has radiographic cavitation (93, 161). Pulmonary function testing is often impaired on disease onset, but the pattern of impairment may be either obstructive or restrictive (105).

As with many idiopathic eosinophilic syndromes, the mainstay of treatment is corticosteroid therapy. While the improvement in symptoms and infiltrates with corticosteroids is rapid, relapses are common with attempts to taper the steroid dosage (121). Inter- 
A

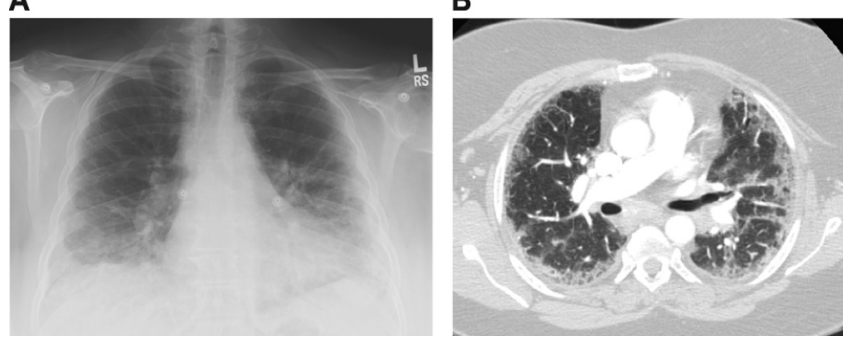

FIG 2 Representative chest X-ray (A) and CT scan (B) of chronic eosinophilic pneumonia.

estingly, patients with asthma in addition to CEP have been observed to have lower rates of relapse, perhaps due to high doses of inhaled corticosteroids (104). Pulmonary function testing may remain abnormal with an obstructive pattern, despite symptomatic and radiographic improvement (41). CEP may rarely progress to lung fibrosis $(41,218)$. It should also be noted that CEP shares many features with Churg-Strauss syndrome (discussed below), with CEP in some cases possibly representing a prodrome for the development of Churg-Strauss syndrome (105).

\section{AEP}

As the name implies, acute eosinophilic pneumonia (AEP) is characterized by a rapidly progressive infiltration of eosinophils into the lungs, leading to respiratory failure, distinguishing it from the more indolent and less severe presentation of chronic eosinophilic pneumonia. AEP is a relatively recently described phenomenon, with the initial cases reported in $1989(4,6)$. Allen et al. described a series of four patients who presented acutely with fever, severe hypoxemia, bilateral pulmonary infiltrates, and BAL fluid eosinophilia in the absence of identifiable infectious causes and whose symptoms resolved rapidly with corticosteroid therapy (4). As with CEP, the early reports of AEP remain representative of the contemporary understanding of the syndrome.

The underlying mechanisms of AEP are even more poorly understood than those of CEP, though there is significant overlap with CEP in the presence of specific inflammatory mediators in the BAL fluid of patients with AEP. As in CEP, the chemokine CCL17 has been detected in high levels in AEP, potentially consistent with a role for recruited T cells in the pathogenesis of AEP (114). An array of both Th2 and Th1 cytokines are elevated in the BAL fluid in AEP, including IL-1 ra, IL-2, IL-5, IL-10, IL-12, IL-13, and IL-18, perhaps reflecting the known pluripotent secretory potential of eosinophils $(3,76,180)$. In particular, elevated BAL fluid levels of IL-5, the key cytokine promoting differentiation, migration, and survival of eosinophils, are associated with AEP (120, $134,155,184,215)$. Cationic granule proteins and inflammatory lipid mediators are detectable in the urine of subjects with AEP (136). Vascular endothelial growth factor (VEGF) is elevated in the lungs in AEP, consistent with increased vascular permeability contributing to the pathophysiology of the disease (125). BAL fluid eosinophils in AEP have been noted to have an activated phenotype, with upregulation of HLA-DR and CD69 (135). Serum IgG levels, particularly those of the IgG2 and IgG4 subclasses, are lower in patients with AEP than in healthy subjects (110). Though no specific fungal etiologies have been found to underpin

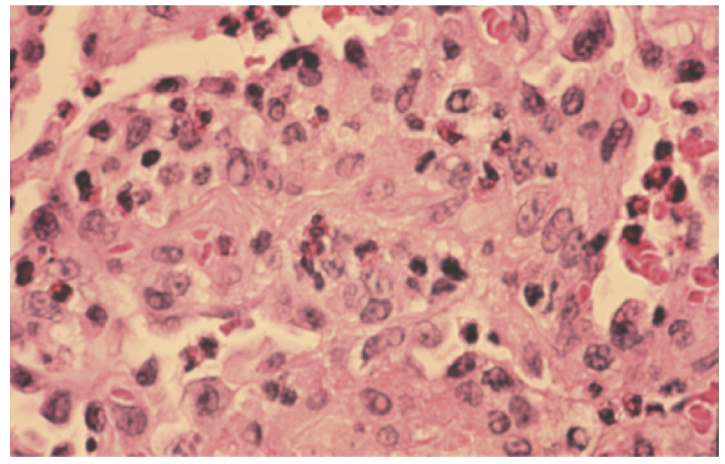

FIG 3 Transbronchial lung biopsy specimen showing acute eosinophilic pneumonia. Numerous infiltrating eosinophils can be seen.

idiopathic AEP, high concentrations of $(1 \rightarrow 3)-\beta$-D-glucan have been observed in the BAL fluid of AEP patients (77).

While the etiology of AEP remains incompletely delineated and no specific inciting agents have been identified, a strong association exists between cigarette smoking, particularly of recent onset, and the development of AEP (171-173, 201, 219). In one AEP case series, 32 of 33 patients were current smokers at disease onset, with 21 patients having started smoking within 1 month of disease onset and 6 others having had recent substantial increases in the quantity of cigarettes smoked (192). Rechallenge with cigarette smoke has been reported to be associated with recurrence of disease (201). Another case series of AEP in U.S. military personnel serving in Iraq featured a history of current smoking in all 18 patients, with recent onset in 14 patients (174). Secondhand smoke exposure, smoking of flavored cigars, and exposure to World Trade Center dust have all also been associated with development of $\operatorname{AEP}(5,87,153)$.

The rapid onset of dyspnea and fever of less than 1 month in duration is characteristic of $\operatorname{AEP}(67,203)$. The condition affects men more commonly than women (67). Hypoxemia and respiratory distress may be severe enough to necessitate initiation of mechanical ventilation $(67,143,203)$. Chest X-rays demonstrate airspace and reticular opacities, usually bilaterally, and CT scans often have a significant component of ground-glass opacification with accompanying septal thickening and thickening of the bronchovascular bundles $(23,33,84,115)$. Obtaining BAL fluid by bronchoscopy is necessary to make the diagnosis, using an eosinophil percentage of $>25 \%$ as the criterion (67). While lung biopsy is not needed diagnostically, pathology may show diffuse alveolar damage along with eosinophilic infiltration (188) (Fig. 3). Peripheral blood eosinophilia is not a necessary diagnostic feature of AEP (203). AEP is exquisitely responsive to corticosteroid therapy, and though reported treatment regimens are variable in dosage and duration, patients do not generally relapse after completion of therapy $(67,147)$.

\section{CSS}

Churg-Strauss syndrome (CSS), also referred to allergic angiitis granulomatosis, is a condition in which eosinophilic vasculitis and infiltration potentially involve multiple organs, including the sinuses, lungs, peripheral nerves, heart, skin, gastrointestinal tract, and kidneys $(28,80,203)$. In many patients, sinusitis and asthmalike symptoms accompanied by peripheral eosinophilia are the presenting constellation of signs and symptoms $(56,92)$. Like 


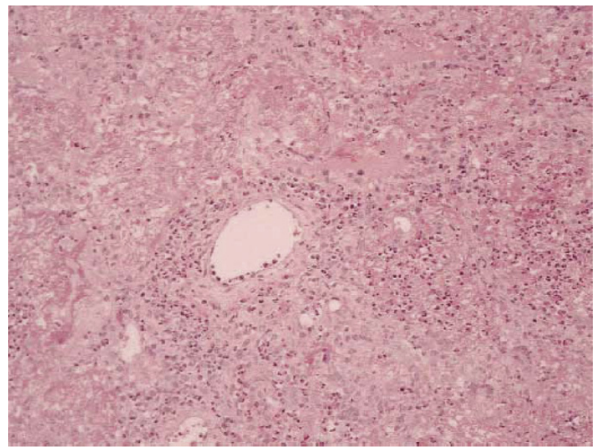

FIG 4 Lung biopsy specimen from a patient with Churg-Strauss syndrome. There is perivascular eosinophilic infiltration; though the vessel itself is relatively spared and granulomata are not present, these findings are consistent with a diagnosis of CSS. (Reprinted from reference 209 with permission from Elsevier.)

the other noninfectious pulmonary eosinophilic syndromes, the pathophysiology of CSS is not fully understood. While antineutrophil cytoplasmic autoantibodies (ANCA) against myeloperoxidase are often seen in CSS, it is unclear if CSS is truly an autoimmune disease $(158,177)$. There is likely an important role of T cells in the pathogenesis of CSS, with Th2 inflammation representing an important component of the disease $(34,65,81,195)$. However, the factors that differentiate CSS from other Th2-driven eosinophilic processes remain incompletely delineated. Eosinophil depletion with anti-IL-5 monoclonal antibodies has shown promising preliminary results in treating CSS, emphasizing the mechanistic importance of IL-5 in the disorder (82). Circulating biomarkers of CSS include IL-25 and the chemokines eotaxin-3 (CCL26) and TARC (thymus and activation-regulated chemokine; also called CCL17), suggesting a potential role for these proteins in CSS pathogenesis $(34,146,189,221)$. Several medications used in the treatment of asthma, including leukotriene modifiers, inhaled corticosteroids, and omalizumab, have been associated with the development of CSS $(95,204-206)$. However, it is likely that these medications do not have a direct causative role in CSS; rather, their initiation accompanies withdrawal or reduction of corticosteroids, which in turn unmasks active CSS, or simply reflects their use in treating the asthma of incipient CSS (203).

Respiratory manifestations are an integral component of CSS, with asthma as a major criterion for all systems that have been implemented for the diagnosis of CSS (203). While presentations are variable, CSS has been described as having a prodromal phase in which asthma and rhinosinusitis are the predominant features. The disease may then progress to an infiltrative phase involving the lungs and other organs, followed by a vasculitic phase $(56,92)$. However, it should be emphasized that such a linear progression is not necessarily observed in patients with CSS. Pulmonary infiltrates on chest imaging are common, and pathology demonstrates eosinophilic infiltration and may show perivascular infiltration or frank vasculitis of small- and medium-size vessels, making CSS an important consideration in the evaluation of pulmonary eosinophilia (Fig. 4) (24, 27, 209, 213). Chest X-ray commonly shows patchy, bilateral, migratory infiltrates (24). CT imaging of the lung parenchyma may show peripheral opacities that are ground glass or consolidative in character $(24,213)$. The commonalities in clinical and radiographic presentation between some patients with
CSS and patients with chronic eosinophilic pneumonia raises the possibility of overlap between these two diagnoses and the potential of CEP to evolve into CSS.

Several sets of diagnostic criteria for CSS have been proposed $(69,92,108)$. Regardless of classification scheme, asthma, eosinophilia, pulmonary infiltrates, and eosinophilic vasculitis are components of establishing the diagnosis. As mentioned above, patients with CSS often have a positive ANCA test result. Inflammatory markers, including the erythrocyte sedimentation rate, Creactive protein, and rheumatoid factor, may be elevated, along with circulating IgE levels (203). Notable extrapulmonary manifestations include mononeuritis multiplex and eosinophilic infiltrative cardiac disease $(56,92)$. CSS has the potential to be a fatal condition, in particular secondary to its cardiac manifestations (123).

Corticosteroids are the mainstay of therapy for CSS, though remissions may be seen with tapering of steroid therapy (150). Cyclophosphamide and several other immunosuppressive agents have been used to treat CSS as adjunctive, potentially steroid-sparing therapies $(47,57,59)$. The use of a monoclonal antibody against IL-5 is an experimental therapy that is not currently commercially available and awaits definitive clinical trials (82).

\section{HES}

The term "hypereosinophilic syndromes" (HES) refers to a range of disorders characterized by elevated numbers of circulating blood eosinophils accompanied by various end-organ infiltration leading to clinical disease $(157,168,208)$. The major subcategories of HES are the myeloproliferative variants and the lymphocytic variants of the disease. While many cases of HES are truly idiopathic, specific etiologies have been identified for some, such as myeloproliferative variant HES due to platelet-derived growth factor $\alpha$ gene rearrangement.

Pulmonary manifestations may occur in up to $40 \%$ of patients with hypereosinophilic syndromes, though only a subset of these patients can truly be grouped in the category of pulmonary eosinophilia with distinct radiographic abnormalities, given that most individuals with HES and cough have clear chest X-rays $(40,208)$. When they are present, infiltrates may occur in any region of the lungs. Biopsy of affected areas may show parenchymal infiltration of eosinophils. Because HES commonly affects the heart, radiographic abnormalities, including interstitial changes and pleural effusions, can often be attributed to congestive heart failure (208). As opposed to many of the other noninfectious causes of eosinophilic pneumonia discussed in this article, corticosteroid therapy may be ineffective in this case, and other immunomodulatory therapies, such as imatinib, are often employed $(86,131)$. A randomized, placebo-controlled trial has demonstrated that specifically targeting eosinophils with a monoclonal antibody against IL-5 is effective as an adjunct therapy for HES, though not yet commercially available (156).

\section{CONCLUSIONS}

Eosinophilic pneumonia can be caused by several infectious etiologies of parasitic origin. The noninfectious etiologies can be categorized into allergic, exposure-related, and idiopathic etiologies (Table 2). The clinical history and careful evaluation of patients allow clinicians to first narrow the potential causes to these broad categories and then to a specific diagnosis. Corticosteroids are an 
TABLE 2 Noninfectious causes of eosinophilic pneumonia

\begin{tabular}{ll}
\hline Etiology & Example \\
\hline Allergic reaction & Allergic bronchopulmonary aspergillosis \\
& Sensitization to other non-Aspergillus fungi \\
Exposures & Drug exposure (e.g., nitrofurantoin, \\
& nonsteroidal anti-inflammatories) \\
& Toxin exposure (e.g., particulate metals, \\
& inhalational drugs of abuse) \\
& Chronic eosinophilic pneumonia \\
Idiopathic etiology & Acute eosinophilic pneumonia \\
& Churg-Strauss syndrome \\
& Hypereosinophilic syndrome \\
\hline
\end{tabular}

important component of the therapy for many of these conditions, both infectious and noninfectious, though they may precipitate hyperinfection syndrome in caes of strongyloidiasis. While anthelmintic therapy is needed for several of the infections discussed, others are self-limited in nature and likely do not require any therapy.

\section{REFERENCES}

1. Agarwal R. 2009. Allergic bronchopulmonary aspergillosis. Chest 135: 805-826.

2. Akuthota P, Wang HB, Spencer LA, Weller PF. 2008. Immunoregulatory roles of eosinophils: a new look at a familiar cell. Clin. Exp. Allergy 38:1254-1263.

3. Allen JN, et al. 1996. Detection of IL-5 and IL-1 receptor antagonist in bronchoalveolar lavage fluid in acute eosinophilic pneumonia. J. Allergy Clin. Immunol. 97:1366-1374.

4. Allen JN, Pacht ER, Gadek JE, Davis WB. 1989. Acute eosinophilic pneumonia as a reversible cause of noninfectious respiratory failure. N. Engl. J. Med. 321:569-574.

5. Al-Saieg N, Moammar O, Kartan R. 2007. Flavored cigar smoking induces acute eosinophilic pneumonia. Chest 131:1234-1237.

6. Badesch DB, King TE, Jr, Schwarz MI. 1989. Acute eosinophilic pneumonia: a hypersensitivity phenomenon? Am. Rev. Respir. Dis. 139:249252.

7. Bargagli E, et al. 2005. Tryptase concentrations in bronchoalveolar lavage from patients with chronic eosinophilic pneumonia. Clin. Sci. (Lond.) 108:273-276.

8. Bartelink AK, Kortbeek LM, Huidekoper HJ, Meulenbelt J, van Knapen F. 1993. Acute respiratory failure due to Toxocara infection. Lancet 342:1234.

9. Beaver PC, Snyder CH, Carrera GM, Dent JH, Lafferty JW. 1952. Chronic eosinophilia due to visceral larva migrans; report of three cases. Pediatrics 9:7-19.

10. Beigel Y, Greenberg Z, Ostfeld I. 2000. Clinical problem-solving. Letting the patient off the hook. N. Engl. J. Med. 342:1658-1661.

11. Beninati W, et al. 1993. Pulmonary eosinophils express HLA-DR in chronic eosinophilic pneumonia. J. Allergy Clin. Immunol. 92:442-449.

12. Bhatia G. 1997. Echinococcus. Semin. Respir. Infect. 12:171-186.

13. Boe DM, Schwarz MI. 2007. A 31-year-old man with chronic cough and hemoptysis. Chest 132:721-726.

14. Boland JM, et al. 2011. Pleuropulmonary infection by Paragonimus westermani in the United States: a rare case of eosinophilic pneumonia after ingestion of live crabs. Am. J. Surg. Pathol. 35:707-713.

15. Boomars KA, et al. 1996. Eosinophil cationic protein and immunoglobulin levels in bronchoalveolar lavage fluid obtained from patients with chronic eosinophilic pneumonia. Eur. Respir. J. 9:2488-2493.

16. Brain L, Allan B. 1964. Encephalitis due to infection with Toxocara canis. Report of a suspected case. Lancet i:1355-1357.

17. Buckingham SJ, Hansell DM. 2003. Aspergillus in the lung: diverse and coincident forms. Eur. Radiol. 13:1786-1800.

18. Campbell MJ, Clayton YM. 1964. Bronchopulmonary aspergillosis. A correlation of the clinical and laboratory findings in 272 patients investigated for bronchopulmonary aspergillosis. Am. Rev. Respir. Dis. 89: $186-196$.
19. Carrington CB, et al. 1969. Chronic eosinophilic pneumonia. N. Engl. J. Med. 280:787-798.

20. Chan-Yeung M, Chase WH, Trapp W, Grzybowski S. 1971. Allergic bronchopulmonary aspergillosis. Clinical and pathologic study of three cases. Chest 59:33-39.

21. Chapman BJ, Capewell S, Gibson R, Greening AP, Crompton GK. 1989. Pulmonary eosinophilia with and without allergic bronchopulmonary aspergillosis. Thorax 44:919-924.

22. Chauhan B, Knutsen A, Hutcheson PS, Slavin RG, Bellone CJ. 1996. T cell subsets, epitope mapping, and HLA-restriction in patients with allergic bronchopulmonary aspergillosis. J. Clin. Invest. 97:2324-2331.

23. Cheon JE, Lee KS, Jung GS, Chung MH, Cho YD. 1996. Acute eosinophilic pneumonia: radiographic and CT findings in six patients. AJR Am. J. Roentgenol. 167:1195-1199.

24. Choi YH, et al. 2000. Thoracic manifestation of Churg-Strauss syndrome: radiologic and clinical findings. Chest 117:117-124.

25. Chu E, Whitlock WL, Dietrich RA. 1990. Pulmonary hyperinfection syndrome with Strongyloides stercoralis. Chest 97:1475-1477.

26. Chung YB, Kita H, Shin MH. 2008. A 27 kDa cysteine protease secreted by newly excysted Paragonimus westermani metacercariae induces superoxide anion production and degranulation of human eosinophils. Korean J. Parasitol. 46:95-99.

27. Churg A. 2001. Recent advances in the diagnosis of Churg-Strauss syndrome. Mod. Pathol. 14:1284-1293.

28. Churg J, Strauss L. 1951. Allergic granulomatosis, allergic angiitis, and periarteritis nodosa. Am. J. Pathol. 27:277-301.

29. Cintron-Rivera AA, et al. 1956. Acute Manson's schistosomiasis. Am. J. Med. 21:918-943.

30. Clark WD, Cox PM, Jr, Ratner LH, Correa-Coronas R. 1970. Acute schistosomiasis mansoni in 10 boys. An outbreak in Caguas, Puerto Rico. Ann. Intern. Med. 73:379-385.

31. Clutterbuck EJ, Sanderson CJ. 1988. Human eosinophil hematopoiesis studied in vitro by means of murine eosinophil differentiation factor (IL5): production of functionally active eosinophils from normal human bone marrow. Blood 71:646-651.

32. Culley FJ, Brown A, Girod N, Pritchard DI, Williams TJ. 2002. Innate and cognate mechanisms of pulmonary eosinophilia in helminth infection. Eur. J. Immunol. 32:1376-1385.

33. Daimon T, et al. 2008. Acute eosinophilic pneumonia: thin-section CT findings in 29 patients. Eur. J. Radiol. 65:462-467.

34. Dallos T, et al. 2010. CCL17/thymus and activation-related chemokine in Churg-Strauss syndrome. Arthritis Rheum. 62:3496-3503.

35. Del Giudice P, et al. 2002. Loeffler's syndrome and cutaneous larva migrans: a rare association. Br. J. Dermatol. 147:386-388.

36. Despommier D. 2003. Toxocariasis: clinical aspects, epidemiology, medical ecology, and molecular aspects. Clin. Microbiol. Rev. 16:265272.

37. Deviller P, et al. 1991. Detection of an eosinophil derived neurotoxin in the urine of a patient with idiopathic chronic eosinophilic pneumonia. Clin. Chim. Acta 201:105-112.

38. Diemert DJ. 2011. Ascariasis, p 794-798. In Guerrant RL, Walker DH, Weller PF (ed), Tropical infectious diseases: principles, pathogens \& practice, 3rd ed. Churchill Livingstone, Philadelphia, PA.

39. Dold C, Holland CV. 2011. Ascaris and ascariasis. Microbes Infect. 13:632-637.

40. Dulohery MM, Patel RR, Schneider F, Ryu JH. 2011. Lung involvement in hypereosinophilic syndromes. Respir. Med. 105:114-121.

41. Durieu J, Wallaert B, Tonnel AB. 1997. Long-term follow-up of pulmonary function in chronic eosinophilic pneumonia. Eur. Respir. J. 10: 286-291.

42. Erwin GE, Fitzgerald JE. 2007. Case report: allergic bronchopulmonary aspergillosis and allergic fungal sinusitis successfully treated with voriconazole. J. Asthma 44:891-895.

43. Ferreira MS, et al. 1999. Strongyloidiasis and infection due to human immunodeficiency virus: 25 cases at a Brazilian teaching hospital, including seven cases of hyperinfection syndrome. Clin. Infect. Dis. 28:154155.

44. Ford J, Reiss-Levy E, Clark E, Dyson AJ, Schonell M. 1981. Pulmonary strongyloidiasis and lung abscess. Chest 79:239-240.

45. Fraser RS, Paré PD. 1999. Fraser and Paré's diagnosis of diseases of the chest, 4th ed. W. B. Saunders, Philadelphia, PA.

46. Furuiye M, et al. 2010. Churg-Strauss syndrome versus chronic eosino- 
philic pneumonia on high-resolution computed tomographic findings. J. Comput. Assist. Tomogr. 34:19-22.

47. Gayraud M, et al. 1997. Treatment of good-prognosis polyarteritis nodosa and Churg-Strauss syndrome: comparison of steroids and oral or pulse cyclophosphamide in 25 patients. Br. J. Rheumatol. 36:1290-1297.

48. Gelpi AP, Mustafa A. 1968. Ascaris pneumonia. Am. J. Med. 44:377389.

49. Ghosh K. 2007. Strongyloides stercoralis septicaemia following steroid therapy for eosinophilia: report of three cases. Trans. R. Soc. Trop. Med. Hyg. 101:1163-1165.

50. Gibson PG, et al. 2003. Induced sputum IL-8 gene expression, neutrophil influx and MMP-9 in allergic bronchopulmonary aspergillosis. Eur. Respir. J. 21:582-588.

51. Gompels MM, Todd J, Peters BS, Main J, Pinching AJ. 1991. Disseminated strongyloidiasis in AIDS: uncommon but important. AIDS 5:329-332.

52. Gonzalez EB, Swedo JL, Rajaraman S, Daniels JC, Grant JA. 1987. Ultrastructural and immunohistochemical evidence for release of eosinophilic granules in vivo: cytotoxic potential in chronic eosinophilic pneumonia. J. Allergy Clin. Immunol. 79:755-762.

53. Grantham JG, Meadows JA, 3rd, Gleich GJ. 1986. Chronic eosinophilic pneumonia. Evidence for eosinophil degranulation and release of major basic protein. Am. J. Med. 80:89-94.

54. Greenberger PA. 2002. Allergic bronchopulmonary aspergillosis. J. Allergy Clin. Immunol. 110:685-692.

55. Greenberger PA, Patterson R. 1988. Allergic bronchopulmonary aspergillosis and the evaluation of the patient with asthma. J. Allergy Clin. Immunol. 81:646-650.

56. Guillevin L, et al. 1999. Churg-Strauss syndrome. Clinical study and long-term follow-up of 96 patients. Medicine (Baltimore) 78:26-37.

57. Guillevin L, et al. 1991. Longterm followup after treatment of polyarteritis nodosa and Churg-Strauss angiitis with comparison of steroids, plasma exchange and cyclophosphamide to steroids and plasma exchange. A prospective randomized trial of 71 patients. J. Rheumatol. 18:567-574.

58. Harris RA, Jr, Musher DM, Fainstein V, Young EJ, Clarridge J. 1980. Disseminated strongyloidiasis. Diagnosis made by sputum examination. JAMA 244:65-66.

59. Hellmich B, Gross WL. 2004. Recent progress in the pharmacotherapy of Churg-Strauss syndrome. Expert Opin. Pharmacother. 5:25-35.

60. Higenbottam TW, Heard BE. 1976. Opportunistic pulmonary strongyloidiasis complicating asthma treated with steroids. Thorax 31:226-233.

61. Hotez PJ. 2011. Hookworm infections, p 799-804. In Guerrant RL, Walker DH, Weller PF (ed), Tropical infectious diseases: principles, pathogens \& practice, 3rd ed. Churchill Livingstone, Philadelphia, PA.

62. Huntley CC, Costas MC, Lyerly A. 1965. Visceral larva migrans syndrome: clinical characteristics and immunologic studies in 51 patients. Pediatrics 36:523-536.

63. Im JG, et al. 1993. Pulmonary paragonimiasis: clinical and experimental studies. Radiographics 13:575-586.

64. Im JG, et al. 1992. Pleuropulmonary paragonimiasis: radiologic findings in 71 patients. AJR Am. J. Roentgenol. 159:39-43.

65. Jakiela B, et al. 2011. Both Th2 and Th17 responses are involved in the pathogenesis of Churg-Strauss syndrome. Clin. Exp. Rheumatol. 29: S23-S34.

66. Janin A, et al. 1993. Segregation of eosinophil proteins in alveolar macrophage compartments in chronic eosinophilic pneumonia. Thorax 48: $57-62$.

67. Janz DR, O’Neal HR, Jr, Ely EW. 2009. Acute eosinophilic pneumonia: a case report and review of the literature. Crit. Care Med. 37:1470-1474.

68. Jederlinic PJ, Sicilian L, Gaensler EA. 1988. Chronic eosinophilic pneumonia. A report of 19 cases and a review of the literature. Medicine (Baltimore) 67:154-162.

69. Jennette JC, et al. 1994. Nomenclature of systemic vasculitides. Proposal of an international consensus conference. Arthritis Rheum. 37:187-192.

70. Jeon K, et al. 2005. Clinical features of recently diagnosed pulmonary paragonimiasis in Korea. Chest 128:1423-1430.

71. Johnson RJ, Jong EC, Dunning SB, Carberry WL, Minshew BH. 1985. Paragonimiasis: diagnosis and the use of praziquantel in treatment. Rev. Infect. Dis. 7:200-206.

72. Kanpittaya J, et al. 2010. Different chest radiographic findings of pulmonary paragonimiasis in two endemic countries. Am. J. Trop. Med. Hyg. 83:924-926.
73. Katoh S, et al. 2005. Accumulation of CXCR3-expressing eosinophils and increased concentration of its ligands (IP10 and Mig) in bronchoalveolar lavage fluid of patients with chronic eosinophilic pneumonia. Int. Arch. Allergy Immunol. 137:229-235.

74. Katoh S, et al. 2003. Accumulation of CCR4-expressing CD4+ T cells and high concentration of its ligands (TARC and MDC) in bronchoalveolar lavage fluid of patients with eosinophilic pneumonia. Allergy 58: $518-523$.

75. Katoh S, et al. 2000. Elevated chemokine levels in bronchoalveolar lavage fluid of patients with eosinophilic pneumonia. J. Allergy Clin. Immunol. 106:730-736.

76. Katoh S, Matsumoto N, Matsumoto K, Fukushima K, Matsukura S. 2004. Elevated interleukin-18 levels in bronchoalveolar lavage fluid of patients with eosinophilic pneumonia. Allergy 59:850-856.

77. Kawayama T, Fujiki R, Honda J, Rikimaru T, Aizawa H. 2003. High concentration of $(1 \rightarrow 3)$-beta-D-glucan in BAL fluid in patients with acute eosinophilic pneumonia. Chest 123:1302-1307.

78. Kayes SG. 1997. Human toxocariasis and the visceral larva migrans syndrome: correlative immunopathology. Chem. Immunol. 66:99-124.

79. Keiser PB, Nutman TB. 2004. Strongyloides stercoralis in the immunocompromised population. Clin. Microbiol. Rev. 17:208-217.

80. Keogh KA, Specks U. 2006. Churg-Strauss syndrome. Semin. Respir. Crit. Care Med. 27:148-157.

81. Kiene M, et al. 2001. Elevated interleukin-4 and interleukin-13 production by $\mathrm{T}$ cell lines from patients with Churg-Strauss syndrome. Arthritis Rheum. 44:469-473.

82. Kim S, Marigowda G, Oren E, Israel E, Wechsler ME. 2010. Mepolizumab as a steroid-sparing treatment option in patients with ChurgStrauss syndrome. J. Allergy Clin. Immunol. 125:1336-1343.

83. Kim TS, et al. 2005. Pleuropulmonary paragonimiasis: CT findings in 31 patients. AJR Am. J. Roentgenol. 185:616-621.

84. King MA, Pope-Harman AL, Allen JN, Christoforidis GA, Christoforidis AJ. 1997. Acute eosinophilic pneumonia: radiologic and clinical features. Radiology 203:715-719.

85. Kita H, et al. 1996. Cytokine production at the site of disease in chronic eosinophilic pneumonitis. Am. J. Respir. Crit. Care Med. 153:14371441.

86. Klion AD, et al. 2006. Approaches to the treatment of hypereosinophilic syndromes: a workshop summary report. J. Allergy Clin. Immunol. 117: 1292-1302.

87. Komiya K, et al. 2010. A case of acute eosinophilic pneumonia following short-term passive smoking: an evidence of very high level of urinary cotinine. Allergol. Int. 59:421-423.

88. Kreindler JL, et al. 2010. Vitamin D3 attenuates Th2 responses to Aspergillus fumigatus mounted by CD4+ T cells from cystic fibrosis patients with allergic bronchopulmonary aspergillosis. J. Clin. Invest. 120:32423254.

89. Kurashima K, et al. 1997. A specific elevation of RANTES in bronchoalveolar lavage fluids of patients with chronic eosinophilic pneumonia. Lab. Invest. 76:67-75.

90. Lal RB, Ottesen EA. 1988. Enhanced diagnostic specificity in human filariasis by IgG4 antibody assessment. J. Infect. Dis. 158:1034-1037.

91. Lane MA, et al. 2009. Human paragonimiasis in North America following ingestion of raw crayfish. Clin. Infect. Dis. 49:e55-e61.

92. Lanham JG, Elkon KB, Pusey CD, Hughes GR. 1984. Systemic vasculitis with asthma and eosinophilia: a clinical approach to the ChurgStrauss syndrome. Medicine (Baltimore) 63:65-81.

93. Laufs U, Schneider C, Wassermann K, Erdmann E. 1998. Chronic eosinophilic pneumonia with atypical radiographic presentation. Respiration 65:323-326.

94. Lebecque P, Leonard A, Argaz M, Godding V, Pilette C. 2009. Omalizumab for exacerbations of allergic bronchopulmonary aspergillosis in patients with cystic fibrosis. BMJ Case Rep. 2009:bcr07.2008.0379. doi: $10.1136 /$ bcr.07.2008.0379.

95. Le Gall C, et al. 2000. Inhaled corticosteroids and Churg-Strauss syndrome: a report of five cases. Eur. Respir. J. 15:978-981.

96. Lenczner M, Spaulding WB, Sanders DE. 1964. Pulmonary manifestations of parasitic infestations. Can. Med. Assoc. J. 91:421-434.

97. Lessnau KD, Can S, Talavera W. 1993. Disseminated Strongyloides stercoralis in human immunodeficiency virus-infected patients. Treatment failure and a review of the literature. Chest 104:119-122.

98. Loffler W. 1956. Transient lung infiltrations with blood eosinophilia. Int. Arch. Allergy Appl. Immunol. 8:54-59. 
99. Lombard CM, Tazelaar HD, Krasne DL. 1987. Pulmonary eosinophilia in coccidioidal infections. Chest 91:734-736.

100. Mahanty S, Maclean JD, Cross JH. 2011. Liver, lung, and intestinal fluke infections, p 854-867. In Guerrant RL, Walker DH, Weller PF (ed), Tropical infectious diseases: principles, pathogens \& practice, 3rd ed. Churchill Livingstone, Philadelphia, PA.

101. Makris AN, Sher S, Bertoli C, Latour MG. 1993. Pulmonary strongyloidiasis: an unusual opportunistic pneumonia in a patient with AIDS. AJR Am. J. Roentgenol. 161:545-547.

102. Malo JL, Hawkins R, Pepys J. 1977. Studies in chronic allergic bronchopulmonary aspergillosis. 1. Clinical and physiological findings. Tho$\operatorname{rax} 32: 254-261$.

103. Mamere AE, et al. 2004. Disseminated cysticercosis with pulmonary involvement. J. Thorac. Imaging 19:109-111.

104. Marchand E, et al. 2003. Idiopathic chronic eosinophilic pneumonia and asthma: how do they influence each other? Eur. Respir. J. 22:8-13.

105. Marchand E, et al. 1998. Idiopathic chronic eosinophilic pneumonia. A clinical and follow-up study of 62 cases. Medicine (Baltimore) 77:299_ 312.

106. Mariano EG, Borja SR, Vruno MJ. 1986. A human infection with Paragonimus kellicotti (lung fluke) in the United States. Am. J. Clin. Pathol. 86:685-687.

107. Maruyama H, Nawa Y, Noda S, Mimori T, Choi WY. 1996. An outbreak of visceral larva migrans due to Ascaris suum in Kyushu, Japan. Lancet 347:1766-1767.

108. Masi AT, et al. 1990. The American College of Rheumatology 1990 criteria for the classification of Churg-Strauss syndrome (allergic granulomatosis and angiitis). Arthritis Rheum. 33:1094-1100.

109. Matsuno O, et al. 2007. Elevated soluble ADAM8 in bronchoalveolar lavage fluid in patients with eosinophilic pneumonia. Int. Arch. Allergy Immunol. 142:285-290.

110. Matsuno O, et al. 2008. Reduced IgG levels found during acute eosinophilic pneumonia, which normalize during recovery from disease. Respir. Med. 102:899-903.

111. Maxwell C, et al. 1987. The clinical and immunologic responses of normal human volunteers to low dose hookworm (Necator americanus) infection. Am. J. Trop. Med. Hyg. 37:126-134.

112. Mayo JR, Muller NL, Road J, Sisler J, Lillington G. 1989. Chronic eosinophilic pneumonia: CT findings in six cases. AJR Am. J. Roentgenol. 153:727-730.

113. McCarthy JS, Moore TA. 2011. Toxocariasis and larva migrans syndromes, p 763-767. In Guerrant RL, Walker DH, Weller PF (ed), Tropical infectious diseases: principles, pathogens \& practice, $3 \mathrm{rd}$ ed. Churchill Livingstone, Philadelphia, PA.

114. Miyazaki E, et al. 2002. Elevated levels of thymus- and activationregulated chemokine in bronchoalveolar lavage fluid from patients with eosinophilic pneumonia. Am. J. Respir. Crit. Care Med. 165:1125-1131.

115. Mochimaru H, Kawamoto M, Fukuda Y, Kudoh S. 2005. Clinicopathological differences between acute and chronic eosinophilic pneumonia. Respirology 10:76-85.

116. Mokhlesi B, Shulzhenko O, Garimella PS, Kuma L, Monti C. 2004. Pulmonary strongyloidiasis: the varied clinical presentations. Clin. Pulm. Med. 11:6-13.

117. More SJ, Copeman DB. 1990. A highly specific and sensitive monoclonal antibody-based ELISA for the detection of circulating antigen in bancroftian filariasis. Trop. Med. Parasitol. 41:403-406.

118. Mukae H, Kadota J, Kohno S, Matsukura S, Hara K. 1995. Increase of activated T-cells in BAL fluid of Japanese patients with bronchiolitis obliterans organizing pneumonia and chronic eosinophilic pneumonia. Chest 108:123-128.

119. Nadeem S, Nasir N, Israel RH. 1994. Loffler's syndrome secondary to crack cocaine. Chest 105:1599-1600.

120. Nakahara Y, Hayashi S, Fukuno Y, Kawashima M, Yatsunami J. 2001. Increased interleukin-5 levels in bronchoalveolar lavage fluid is a major factor for eosinophil accumulation in acute eosinophilic pneumonia. Respiration 68:389-395.

121. Naughton M, Fahy J, FitzGerald MX. 1993. Chronic eosinophilic pneumonia. A long-term follow-up of 12 patients. Chest 103:162-165.

122. Neeld DA, Goodman LR, Gurney JW, Greenberger PA, Fink JN. 1990. Computerized tomography in the evaluation of allergic bronchopulmonary aspergillosis. Am. Rev. Respir. Dis. 142:1200-1205.

123. Neumann T, et al. 2009. Cardiac involvement in Churg-Strauss syndrome: impact of endomyocarditis. Medicine (Baltimore) 88:236-243.
124. Nichols D, et al. 1979. Acute and chronic pulmonary function changes in allergic bronchopulmonary aspergillosis. Am. J. Med. 67:631-637.

125. Nishigaki Y, et al. 2003. Increased vascular endothelial growth factor in acute eosinophilic pneumonia. Eur. Respir. J. 21:774-778.

126. Nutman TB, Kazura JW. 2011. Lymphatic filariasis, p 729-734. In Guerrant RL, Walker DH, Weller PF (ed), Tropical infectious diseases: principles, pathogens \& practice, 3 rd ed. Churchill Livingstone, Philadelphia, PA.

127. Nutman TB, et al. 1989. Tropical pulmonary eosinophilia: analysis of antifilarial antibody localized to the lung. J. Infect. Dis. 160:1042-1050.

128. Nwokolo C, Imohiosen EA. 1973. Strongyloidiasis of respiratory tract presenting as "asthma". Br. Med. J. 2:153-154.

129. O’Bryan L, et al. 2003. Localized eosinophil degranulation mediates disease in tropical pulmonary eosinophilia. Infect. Immun. 71:13371342 .

130. Ogakwu M, Nwokolo C. 1973. Radiological findings in pulmonary paragonimiasis as seen in Nigeria: a review based on one hundred cases. Br. J. Radiol. 46:699-705.

131. Ogbogu PU, et al. 2009. Hypereosinophilic syndrome: a multicenter, retrospective analysis of clinical characteristics and response to therapy. J. Allergy Clin. Immunol. 124:1319-1325.

132. Ogushi F, Ozaki T, Kawano T, Yasuoka S. 1987. PGE2 and PGF2 alpha content in bronchoalveolar lavage fluid obtained from patients with eosinophilic pneumonia. Chest 91:204-206.

133. Okada F, et al. 2007. Pulmonary computed tomography findings of visceral larva migrans caused by Ascaris suum. J. Comput. Assist. Tomogr. 31:402-408.

134. Okubo Y, et al. 1998. Predominant implication of IL-5 in acute eosinophilic pneumonia: comparison with chronic eosinophilic pneumonia. Int. Arch. Allergy Immunol. 116:76-80.

135. Okubo Y, et al. 1995. Adhesion molecules on eosinophils in acute eosinophilic pneumonia. Am. J. Respir. Crit. Care Med. 151:1259-1262.

136. Ono E, et al. 2008. Increased urinary leukotriene E4 concentration in patients with eosinophilic pneumonia. Eur. Respir. J. 32:437-442.

137. Ottesen EA. 1985. Efficacy of diethylcarbamazine in eradicating infection with lymphatic-dwelling filariae in humans. Rev. Infect. Dis. 7:341356.

138. Ottesen EA, Nutman TB. 1992. Tropical pulmonary eosinophilia. Annu. Rev. Med. 43:417-424.

139. Ottesen EA, Weller PF. 1979. Eosinophilia following treatment of patients with schistosomiasis mansoni and Bancroft's filariasis. J. Infect. Dis. 139:343-347.

140. Pachucki CT, Levandowski RA, Brown VA, Sonnenkalb BH, Vruno MJ. 1984. American paragonimiasis treated with praziquantel. N. Engl. J. Med. 311:582-583.

141. Pasricha JM, Street AC, Leder K. 2011. A rash and cough in a traveler. Clin. Infect. Dis. 53:167, 205-206.

142. Petithory JC. 1996. Can Ascaris suum cause visceral larva migrans? Lancet 348:689.

143. Philit F, et al. 2002. Idiopathic acute eosinophilic pneumonia: a study of 22 patients. Am. J. Respir. Crit. Care Med. 166:1235-1239.

144. Phills JA, Harrold AJ, Whiteman GV, Perelmutter L. 1972. Pulmonary infiltrates, asthma and eosinophilia due to Ascaris suum infestation in man. N. Engl. J. Med. 286:965-970.

145. Pinkston P, et al. 1987. Acute tropical pulmonary eosinophilia. Characterization of the lower respiratory tract inflammation and its response to therapy. J. Clin. Invest. 80:216-225.

146. Polzer K, et al. 2008. Eotaxin-3 is involved in Churg-Strauss syn drome-a serum marker closely correlating with disease activity. Rheumatology (Oxford) 47:804-808.

147. Pope-Harman AL, Davis WB, Allen ED, Christoforidis AJ, Allen JN. 1996. Acute eosinophilic pneumonia. A summary of 15 cases and review of the literature. Medicine (Baltimore) 75:334-342.

148. Rassiga AL, Lowry JL, Forman WB. 1974. Diffuse pulmonary infection due to Strongyloides stercoralis. JAMA 230:426-427.

149. Reiff DB, Wells AU, Carr DH, Cole PJ, Hansell DM. 1995. CT findings in bronchiectasis: limited value in distinguishing between idiopathic and specific types. AJR Am. J. Roentgenol. 165:261-267.

150. Ribi C, et al. 2008. Treatment of Churg-Strauss syndrome without poor-prognosis factors: a multicenter, prospective, randomized, openlabel study of seventy-two patients. Arthritis Rheum. 58:586-594.

151. Riscili BP, Wood KL. 2009. Noninvasive pulmonary Aspergillus infections. Clin. Chest Med. 30:315-335. 
152. Rom WN, et al. 1990. Persistent lower respiratory tract inflammation associated with interstitial lung disease in patients with tropical pulmonary eosinophilia following conventional treatment with diethylcarbamazine. Am. Rev. Respir. Dis. 142:1088-1092.

153. Rom WN, et al. 2002. Acute eosinophilic pneumonia in a New York City firefighter exposed to World Trade Center dust. Am. J. Respir. Crit. Care Med. 166:797-800.

154. Rosenberg M, et al. 1977. Clinical and immunologic criteria for the diagnosis of allergic bronchopulmonary aspergillosis. Ann. Intern. Med. 86:405-414.

155. Rothenberg ME, Hogan SP. 2006. The eosinophil. Annu. Rev. Immunol. 24:147-174.

156. Rothenberg ME, et al. 2008. Treatment of patients with the hypereosinophilic syndrome with mepolizumab. N. Engl. J. Med. 358:1215-1228.

157. Roufosse F, Cogan E, Goldman M. 2004. Recent advances in pathogenesis and management of hypereosinophilic syndromes. Allergy 59:673689.

158. Sable-Fourtassou R, et al. 2005. Antineutrophil cytoplasmic antibodies and the Churg-Strauss syndrome. Ann. Intern. Med. 143:632-638.

159. Saita N, Yamanaka T, Kohrogi H, Ando M, Hirashima M. 2001. Apoptotic response of eosinophils in chronic eosinophilic pneumonia. Eur. Respir. J. 17:190-194.

160. Sakai S, et al. 2006. Pulmonary lesions associated with visceral larva migrans due to Ascaris suum or Toxocara canis: imaging of six cases. AJR Am. J. Roentgenol. 186:1697-1702.

161. Samman YS, Wali SO, Abdelaal MA, Gangi MT, Krayem AB. 2001 Chronic eosinophilic pneumonia presenting with recurrent massive bilateral pleural effusion: case report. Chest 119:968-970.

162. Sanderson CJ, Warren DJ, Strath M. 1985. Identification of a lymphokine that stimulates eosinophil differentiation in vitro. Its relationship to interleukin 3, and functional properties of eosinophils produced in cultures. J. Exp. Med. 162:60-74.

163. Schad GA, et al. 1973. Arrested development in human hookworm infections: an adaptation to a seasonally unfavorable external environment. Science 180:502-504.

164. Schaeffer MW, et al. 2004. Strongyloides hyperinfection syndrome after heart transplantation: case report and review of the literature. J. Heart Lung Transplant. 23:905-911.

165. Schwartz HJ, Greenberger PA. 1991. The prevalence of allergic bronchopulmonary aspergillosis in patients with asthma, determined by serologic and radiologic criteria in patients at risk. J. Lab. Clin. Med. 117: $138-142$.

166. Schwarz YA, et al. 1994. Eosinophilic lung reaction to aluminium and hard metal. Chest 105:1261-1263.

167. Shah PK, Lakhotia M, Chittora M, Mehta S, Purohit A. 1989. Pulmonary infiltration with blood eosinophilia after scorpion sting. Chest 95 : 691-692.

168. Sheikh J, Weller PF. 2007. Clinical overview of hypereosinophilic syndromes. Immunol. Allergy Clin. North Am. 27:333-355.

169. Shijubo N, Shigehara K, Hirasawa M, Inuzuka M, Abe S. 1994. Eosinophilic cationic protein in chronic eosinophilic pneumonia and eosinophilic granuloma. Chest 106:1481-1486.

170. Shimizudani N, et al. 2001. Analysis of $\mathrm{T}$ cell receptor $\mathrm{V}$ (beta) gene expression and clonality in bronchoalveolar fluid lymphocytes from a patient with chronic eosinophilic pneumonitis. Lung 179:31-41.

171. Shintani H, Fujimura M, Ishiura Y, Noto M. 2000. A case of cigarette smoking-induced acute eosinophilic pneumonia showing tolerance. Chest 117:277-279.

172. Shintani H, et al. 2000. Acute eosinophilic pneumonia caused by cigarette smoking. Intern. Med. 39:66-68.

173. Shiota Y, et al. 2000. Acute eosinophilic pneumonia following cigarette smoking. Intern. Med. 39:830-833.

174. Shorr AF, et al. 2004. Acute eosinophilic pneumonia among US military personnel deployed in or near Iraq. JAMA 292:2997-3005.

175. Siddiqui AA, Genta RM, Maguilnik I, Berk SL. 2011. Strongyloidiasis, p 805-812. In Guerrant RL, Walker DH, Weller PF (ed), Tropical infectious diseases: principles, pathogens \& practice, 3rd ed. Churchill Livingstone, Philadelphia, PA.

176. Singcharoen T, Rawd-Aree P, Baddeley H. 1988. Computed tomography findings in disseminated paragonimiasis. Br. J. Radiol. 61:83-86.

177. Sinico RA, et al. 2005. Prevalence and clinical significance of antineutrophil cytoplasmic antibodies in Churg-Strauss syndrome. Arthritis Rheum. 52:2926-2935.
178. Slavin RG, et al. 1988. A pathologic study of allergic bronchopulmonary aspergillosis. J. Allergy Clin. Immunol. 81:718-725.

179. Solomon J, Schwarz M. 2006. Drug-, toxin-, and radiation therapyinduced eosinophilic pneumonia. Semin. Respir. Crit. Care Med. 27: 192-197.

180. Spencer LA, et al. 2009. Human eosinophils constitutively express multiple Th1, Th2, and immunoregulatory cytokines that are secreted rapidly and differentially. J. Leukoc. Biol. 85:117-123.

181. Stevens DA, et al. 2003. Allergic bronchopulmonary aspergillosis in cystic fibrosis - state of the art: Cystic Fibrosis Foundation Consensus Conference. Clin. Infect. Dis. 37(Suppl 3):S225-S264.

182. Stevens DA, et al. 2000. A randomized trial of itraconazole in allergic bronchopulmonary aspergillosis. N. Engl. J. Med. 342:756-762.

183. Tan SK, Liu TT. 2010. Cutaneous larva migrans complicated by Loffler syndrome. Arch. Dermatol. 146:210-212.

184. Taniguchi H, et al. 1999. Activation of lymphocytes and increased interleukin-5 levels in bronchoalveolar lavage fluid in acute eosinophilic pneumonia. Eur. Respir. J. 13:217-220.

185. Taniguchi H, et al. 2001. Elevated IL-5 levels in pleural fluid of patients with paragonimiasis westermani. Clin. Exp. Immunol. 123:94-98.

186. Tateno H, et al. 2001. Eotaxin and monocyte chemoattractant protein-1 in chronic eosinophilic pneumonia. Eur. Respir. J. 17:962-968.

187. Taylor MJ, et al. 2005. Macrofilaricidal activity after doxycycline treatment of Wuchereria bancrofti: a double-blind, randomised placebocontrolled trial. Lancet 365:2116-2121.

188. Tazelaar HD, Linz LJ, Colby TV, Myers JL, Limper AH. 1997. Acute eosinophilic pneumonia: histopathologic findings in nine patients. Am. J. Respir. Crit. Care Med. 155:296-302.

189. Terrier B, et al. 2010. Interleukin-25: a cytokine linking eosinophils and adaptive immunity in Churg-Strauss syndrome. Blood 116:4523-4531.

190. Tillie-Leblond I, et al. 2011. Allergic bronchopulmonary aspergillosis and omalizumab. Allergy 66:1254-1256.

191. Tillie-Leblond I, Tonnel AB. 2005. Allergic bronchopulmonary aspergillosis. Allergy 60:1004-1013.

192. Uchiyama H, et al. 2008. Alterations in smoking habits are associated with acute eosinophilic pneumonia. Chest 133:1174-1180.

193. Udwadia FE. 1975. Pulmonary eosinophilia, p 35-155. In Herzog H (ed), Progress in respiration research, vol 7. Karger, Basel, Switzerland.

194. Upadhyay D, Corbridge T, Jain M, Shah R. 2001. Pulmonary hyperinfection syndrome with Strongyloides stercoralis. Am. J. Med. 111:167169.

195. Vaglio A, Moosig F, Zwerina J. 2012. Churg-Strauss syndrome: update on pathophysiology and treatment. Curr. Opin. Rheumatol. 24:24-30.

196. van der Ent CK, Hoekstra H, Rijkers GT. 2007. Successful treatment of allergic bronchopulmonary aspergillosis with recombinant anti-IgE antibody. Thorax 62:276-277.

197. Vilela EG, et al. 2009. Strongyloides stercoralis hyperinfection syndrome after liver transplantation: case report and literature review. Transpl. Infect. Dis. 11:132-136.

198. Walsh TJ, et al. 2008. Treatment of aspergillosis: clinical practice guidelines of the Infectious Diseases Society of America. Clin. Infect. Dis. 46: 327-360.

199. Wark PA, et al. 2003. Anti-inflammatory effect of itraconazole in stable allergic bronchopulmonary aspergillosis: a randomized controlled trial. J. Allergy Clin. Immunol. 111:952-957.

200. Warringa RA, et al. 1992. Modulation of eosinophil chemotaxis by interleukin-5. Am. J. Respir. Cell Mol. Biol. 7:631-636.

201. Watanabe K, et al. 2002. Acute eosinophilic pneumonia following cigarette smoking: a case report including cigarette-smoking challenge test. Intern. Med. 41:1016-1020.

202. Webb JK, Job CK, Gault EW. 1960. Tropical eosinophilia: demonstration of microfilariae in lung, liver, and lymph nodes. Lancet i:835-842.

203. Wechsler ME. 2007. Pulmonary eosinophilic syndromes. Immunol. Allergy Clin. North Am. 27:477-492.

204. Wechsler ME, et al. 2000. Churg-Strauss syndrome in patients receiving montelukast as treatment for asthma. Chest 117:708-713.

205. Wechsler ME, et al. 1998. Pulmonary infiltrates, eosinophilia, and cardiomyopathy following corticosteroid withdrawal in patients with asthma receiving zafirlukast. JAMA 279:455-457.

206. Wechsler ME, Wong DA, Miller MK, Lawrence-Miyasaki L. 2009. Churg-Strauss syndrome in patients treated with omalizumab. Chest 136:507-518.

207. Weller PF. 1994. Parasitic pneumonias, p 695-714. In Pennington J (ed), 
Respiratory infections: diagnosis and management, 3rd ed. Raven Press, New York, NY.

208. Weller PF, Bubley GJ. 1994. The idiopathic hypereosinophilic syndrome. Blood 83:2759-2779.

209. Weller PF, Plaut M, Taggart V, Trontell A. 2001. The relationship of asthma therapy and Churg-Strauss syndrome: NIH workshop summary report. J. Allergy Clin. Immunol. 108:175-183.

210. Williams J, Nunley D, Dralle W, Berk SL, Verghese A. 1988. Diagnosis of pulmonary strongyloidiasis by bronchoalveolar lavage. Chest 94:643644.

211. Wilson ME, Weller PF. 2011. Eosinophilia, p 939-949. In Guerrant RL, Walker DH, Weller PF (ed), Tropical infectious diseases: principles, pathogens \& practice, 3rd ed. Churchill Livingstone, Philadelphia, PA.

212. Woodring JH, Halfhill H, 2nd, Reed JC. 1994. Pulmonary strongyloidiasis: clinical and imaging features. AJR Am. J. Roentgenol. 162:537542.

213. Worthy SA, Muller NL, Hansell DM, Flower CD. 1998. Churg-Strauss syndrome: the spectrum of pulmonary CT findings in 17 patients. AJR Am. J. Roentgenol. 170:297-300.

214. Wright DO, Gold EM. 1946. Loffler's syndrome associated with creep- ing eruption (cutaneous helminthiasis). Arch. Intern. Med. (Chicago) 78:303-312.

215. Yamaguchi S, et al. 1995. IL-5 predominant in bronchoalveolar lavage fluid and peripheral blood in a patient with acute eosinophilic pneumonia. Intern. Med. 34:65-68.

216. Yamaguchi Y, et al. 1988. Highly purified murine interleukin 5 (IL-5) stimulates eosinophil function and prolongs in vitro survival. IL-5 as an eosinophil chemotactic factor. J. Exp. Med. 167:1737-1742.

217. Yang SP, Huang CT, Cheng CS, Chiang LC. 1959. The clinical and roentgenological courses of pulmonary paragonimiasis. Dis. Chest 36 : 494-508.

218. Yoshida K, et al. 1994. Chronic eosinophilic pneumonia progressing to lung fibrosis. Eur. Respir. J. 7:1541-1544.

219. Youn JS, Kwon JW, Kim BJ, Hong SJ. 2010. Smoking-induced acute eosinophilic pneumonia in a 15-year-old girl: a case report. Allergy Asthma Immunol. Res. 2:144-148.

220. Zander DS. 2005. Allergic bronchopulmonary aspergillosis: an overview. Arch. Pathol. Lab. Med. 129:924-928.

221. Zwerina J, et al. 2011. Eotaxin-3 in Churg-Strauss syndrome: a clinical and immunogenetic study. Rheumatology (Oxford) 50:18231827.
Praveen Akuthota is a member of the Division of Pulmonary, Critical Care, and Sleep Medicine and the Division of Allergy and Inflammation at Beth Israel Deaconess Medical Center, with an appointment as Instructor of Medicine at Harvard Medical School. His research efforts center around basic scientific investigations of eosinophil biology, focused in particular on eosinophils as antigen-presenting cells and on eosinophil chemotaxis. Dr. Akuthota is a practicing intensivist and pulmonologist and has a clinical interest in eosinophilic pulmonary disease.

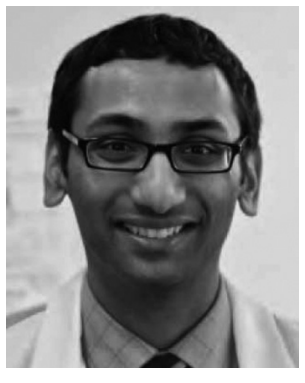

Peter F. Weller is the Chief of the Division of Infectious Disease and the Division of Allergy and Inflammation at Beth Israel Deaconess Medical Center, Professor of Medicine at Harvard Medical School, and Professor of Immunology and Infectious Diseases at the Harvard School of Public Health. He is known internationally as a leading expert on eosinophilic disorders and eosinophil biology. His two principal areas of investigation are (i) the immunobiology of eosinophilic leukocytes and

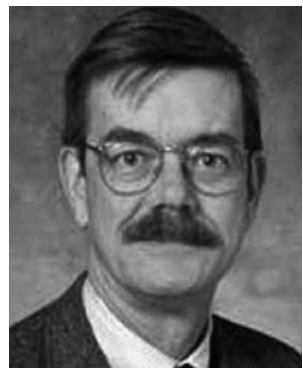

(ii) the intracellular regulation and compartmentalization of inducible mediators of inflammation in neutrophils and other leukocytes. These investigations are pertinent to the roles of eosinophils in allergic and antiparasite immune responses and to the cellular biology of leukocytes underlying their functions in infectious and immune inflammatory responses. 